\title{
Application of Research Study in the Teaching of Civil Engineering
}

\author{
Liu Yan
}

College of Civil Science and Engineering, Yangzhou University, Yangzhou, Jiangsu, 225127

Keywords: Civil engineer specialty; research study; teaching primary exploration.

\begin{abstract}
After the analysis of the characteristics of civil engineering and insufficiencies of traditional teaching method, by combining with the previous results of teaching reform, this paper takes the study of structural courses as an example to make careful design of the learning mode application in civil engineering specialty teaching, and focused on the introduction of teaching ideas, instructional design, teaching points and other teaching contents.

Currently, from the narrow definition, civil engineering includes architectural engineering (or structural engineering), bridge and tunnel engineering, geotechnical engineering, highway and urban roads, railway engineering, etc [1].

As the civil engineering involves a wide range of knowledge, many contents and great difficulty, especially the professional courses, the poor systematic feature, diverse structural forms, a lot of test summaries and conclusions, coupled with insufficient foundation of mathematics and mechanics of some students, the specialty impressed student with difficult mastery in the professional courses learning, thus resulting in poor study effect. To solve this problem, the author of this paper reformed the teaching methods of civil engineering course on the basis of years' teaching practice by careful thought. In the teaching of professional courses, research study approach was used to mobilize the initiative of students, cultivate their ability of independent analysis and problem-solving skills to achieve better teaching results.
\end{abstract}

\section{Characteristics of Modern Civil Engineering and Challenges Faced by Professional Education}

1. Characteristics of modern civil engineering

The characteristics of modern civil engineering are mainly manifested in the following aspects.

(1) Building materials

High-strength lightweight materials continue to emerge. Aluminum alloy, magnesium alloy and glass fiber reinforced plastics (FRP) have begun to be used in civil engineering. In addition, research on improving the steel and concrete strength and durability has achieved remarkable results.

(2) Engineering geology and foundation

The engineering geology, ground structure and stress and mechanical property in natural state is related to the location of construction area, directly determines the basis for design and construction, affects the selection of building materials and upper structural system, with direct impact on underground works. For the exploration technology of engineering geology and foundation, the current practice is still site drilling and sampling and laboratory analysis test, so changes are in urgent need.

(3) Project planning

The previous overall plan was selected from a number of proposals by relying on engineering experience. With the expanding scale of civil engineering facilities, it is necessary to improve the planning level by the use of system engineering theory and methods. Outsize civil engineering, such as tall dam, will cause changes in the natural environment, affect ecological balance and agricultural production, etc, and the social effects of such projects have both advantages and disadvantages. In the planning, we need to make comprehensive consideration of avoiding disadvantages.

(4) Engineering design

Being applicable, economic, safe and beautiful is the basic principle of design. To this end, probability and statistics are used to analyze and determine the load value and material strength 
value, research the time and spatial distribution and statistical law of wind, seismic waves, sea waves, actively develop the analysis of material non-elasticity, structural deformation, structural dynamics and analysis' of joint work between structure and rock and soil, further research and improve structural reliability limit status design method and structure optimization design theory. At the same time, it also focuses on the development of high performance computer-aided design methods.

(5) Engineering construction

With the expansion of the scale of civil engineering and development of construction tools, equipment and machinery towards the orientation of wide varieties, automation, large-scale, the construction has gradually taken the road of mechanization and automation. At the same time, the organization and management started to apply the theory and method of systematic engineering, with a growing trend of scientification. The construction of some projects used structural and component standardization, which not only reduce the cost, shorten construction period, improve labor productivity, but also could solve the construction operational problems under special conditions, so as to build the projects with difficult construction in the past.

In addition, the green, ecological, intelligent building concept and sustainable building concept will have a positive impact on civil engineering.

2. Challenges faced by civil engineering courses

On the characteristics of modern civil engineering features, how to carry out the teaching of professional courses is the challenge faced by professional courses. It is difficult to enable students to master the content of civil engineering courses within the stipulated hours and credits. Traditional teaching methods and classroom teaching is teacher-centered and students are in passive learning, which has obvious deficiencies in the cultivation of students' innovation ability. At the same time, with the increasing hours of practice teaching, theory lessons will be further reduced. Therefore, how to ensure teaching quality requires systematic thinking and design of the professional course teaching [2].

Many graduated civil engineering majors said that in the beginning of work, they didn't know how to embark on the practical engineering problems. It actually reflected the universities' deficiencies in training students' problem analysis ability.

\section{Connotation of Research Study Mode}

In order to train students' ability of problem analysis and problem-solving skills, we need to change the traditional teaching model to introduce research study methods.

"Project-based study" and "problem-based study" are the most frequently applied research study modes [3].

Project-based study is a new mode of classroom teaching. Unlike the traditional teacher-centered, single classroom teaching, it emphasizes student-centered and open learning mode. Problem-based learning is a learning activity based on experience. This learning approach will propose a series of questions based on the course content, and then seek the solution through extensive research and exploration.

The two learning modes require students to take the initiative, research seriously and seek the projects or problems with a variety of solutions and answers. During the course of study, students are divided into groups, with 3 members in each group. The groups are student centered and teachers play the role of mentors and assistants to encourage student to explore boldly. The two study modes can cultivate the students' initiative and help them develop good study habits, and also stress evaluation and assessment based on the student's learning performance.

Sometimes, we can combine the two learning modes to complete the course study.

"Project-based study" and "problem-based study" have the same concept, which are a kind of positive teaching strategy and method. It aims to enable students to develop interest in active learning, improve learning ability, learn to learn, while learning to cooperate with others, collecting data and developing problem-solving skills, thus promoting the healthy growth.

For civil engineering course, professional course teaching can be conducted by the combination 
of two learning methods. Project-based and problem-based study can further tighten the course contents and students are more likely to get some study results during the course learning.

\section{Application of Research Study Mode in Civil Engineering Course Teaching}

In the research study mode, teacher transfers from the role of dominator into the mentor, assistant and facilitator in the teaching process. "Project-based" and "problem-based" research study modes require teachers scientifically and rationally to design the lesson plans according to the course outline and teaching characteristics, mobilize the initiative of student and cultivate their self-learning ability[4] , [5].

1. Basic teaching ideas

Classroom teaching of general civil engineering courses is not easy. After learning the related knowledge of professional courses, students still have limited understanding, let alone the application in engineering. To allow student to truly master the curriculum knowledge and have the ability to solve new problems in the teaching of professional courses, teachers need to use PPT to supplement engineering examples on one hand, and enable students to understand the basic concepts, force characteristics and construction requirements on the other hand. To achieve this purpose of teaching, teachers shall change the classroom teaching of professional courses into the research learning mode combining student individual exploration and group discussion.

2. Teaching design and teaching points

By taking structural professional course teaching as an example, divide the study of civil engineering courses into four phases.

First, before the teaching of professional courses, teachers shall tell student the learning guidance and task in advance and require students to investigate and survey the structure of a building in their hometown (not limited to buildings, bridges and highways) in winter/summer holiday. In addition, they shall analyze the building structure composition characteristics and further learn the structural layout, design the calculation, construction and other knowledge points via the investigation of design institute and construction enterprises and each student must develop a relatively complete PPT courseware. The second is group discussion. Each student shall introduce the research results in terms of the holiday structural system. Through discussion, they need to find out problem, analyze problem by discussion and this phase stresses the formation of knowledge, focusing on the student's independent exploration. The discussion of each group requires complete record. The third is class report. According to the group discussion results, structural system of different forms shall be selected. Students will make presentation in the podium to further expand the structural knowledge, which is a process of knowledge transfer to achieve the purpose of drawing inferences about other cases from one instance. The fourth is the summary made by teacher, which especially stresses the knowledge concerning structural concept design, confirmation principle of structural program, structural layout and structural seismic design and other knowledge points.

In the research investigative study of professional courses, the following teaching points shall be emphasized.

(1) Structural course teaching must include seismic design

Since the outbreak of Wenchuan earthquake in 2008, China has amended the "Seismic Design Specifications", "Concrete Structure Design Specifications", and other related documents, and the seismic design of buildings has been promoted to a new height. In the structural course teaching, the knowledge of structural concept design shall be combined with the basic concepts of structural anti-seismic, emphasize building seismic fortification standards, seismic impact, venue and foundation as well as house location selection. In particular, seismic damages are needed for students to analyze the layout principles of structural system, so as to enable students to master the plane and vertical layout of structural lateral force, lateral stiffness, material strength and other selection rules through research study.

(2) Focus on the organic combination with engineering materials

In the learning of civil engineering course, students are required to know the importance of 
engineering materials, and understand that all engineering structures are composed of basic components, whereas components are formed by materials via certain technical means. Without the progress of material science, there is no development of structural systems.

(3) Learn the integration with mechanics curriculums

The development of civil engineering is closely related to the development of mechanics, building materials and computer. In the research study of civil engineering, students are required to figure out the veins of various structural systems from the perspective of mechanical system, with particular emphasis on the analysis journey from three equations, namely, (physical equation, geometric equation and balance equation). Students shall focus on the association between professional courses and mechanical sources. In the teaching of mechanics courses, teachers shall consciously make assignments concerning internal force calculation of the related beams in the aspect of specialized curriculum design, such as the internal force calculation of continuous beams and plates. Therefore, in the specialized course design, this part of internal forces can be used directly. In this way, students not only review the knowledge of mechanics but also ensure the design quality of the relatively tight course design.

3. Cultivation of comprehensive analysis capabilities

The knowledge of civil engineering is not only structural, but also includes the knowledge of structure, economy, materials and construction. In the research study, students are required to discuss whether the steel structure, concrete structure and wooden structure are applicable to a certain structure, the impact of reasonable form on the external and internal functions of building (bridge) as well as the impact of construction technology, process on the structural system in the aspect of construction.

4. Structural model competition fosters innovation ability

In the research study of civil engineering courses, structural model competition is organized in the structural teaching to develop students' innovation ability. For junior grade students, structural model competition may be the production of the same structural system and the sequence is confirmed according to the load bearing. Students of senior grade are required to design and make structural model. After exerting a certain vertical loads, students can conduct vibration table test to verify the reasonableness of the structural system. Structural model content can foster students' structural awareness and innovation ability.

5. Teaching with the application of multimedia courseware

By visual and auditory performance, multimedia teaching not only saves time for the teacher's writing on the blackboard, but significantly improves the lecture efficiency, especially a large number of engineering examples, building materials, photos or videos in the structural construction process, which completely expresses the issues being difficult to be clarified in traditional teaching via multimedia courseware.

The research study of civil engineering professional courses will help to make the data, pictures, short film and other project cases into PPT, which not only have new documents, large information amount, but have text and illustrations, with good study effect.

6. Course assessment methods

The form of examinations of civil engineering professional course is also an important link needed to be considered in the research study. For course assessment, instead of the traditional examination by a piece of paper, the student's survey results, classroom performance shall be taken as the content for assessment and this part accounts for $40 \%$ of the total score, where the classroom discussion will be scored according to the overall results of each group, and then give each student a score according to individual performance and mutual evaluation between group members.

The rest $60 \%$ requires each student to learn by combining with their own professional courses and report his/his learning experience by reading report or other means. At the same time, teachers shall design the testing questions attentively, which shall truly reflect students' degree of knowledge mastery, and the structural model competition in the learning process is also a part of the results.

This assessment form well reflects the characteristics of research study and the students' fruit of labor. 


\section{Conclusions}

This paper has made exploration of the application of research study mode in the learning of civil engineering courses. The research learning modes of "project-based study" and "problem-based study" has rich teaching content, large amount of information, strong content logic and structure, can better promote students to think positively, and effectively inspire students' interest in learning and researching the professional course as well as team spirit. It can give fully play to the students' innovation ability, develop their structural thinking, structural concepts, problem-solving skills as well as understanding and application ability.

\section{References}

[1]Higher Steering Committee for Civil Engineering, Higher Institution Civil Engineering Undergraduate Guiding Norms[S]. China Building Industry Press, 2011.

[2] Seven ministries, including Ministry of Education, the Central Propaganda Department, Ministry of Finance. Several Opinions on Further Strengthening the Educational Work of the University Practice. JSZ[2012]1

[3] Shan Jiaping. University Research Learning Mode Study [J]. Ningbo University Journal (Educational Science Edition), 2007, 29 (5) :54-56

[4] Sheng Lifang, Wang Qi. Application of Research Learning in Specialized Teaching[J]. Chinese University Teaching, 2009, (9): 60-61.

[5] Chen Jianping, Fan Qinshan, etc. Carry out Research Teaching from the Characteristics of Engineering Foundation Courses [J]. Chinese University Teaching, 2008, (5):20-22. 